\title{
Differentiation of human hair follicle stem cells into endothelial cells induced by vascular endothelial and basic fibroblast growth factors
}

\author{
ZHI CHENG XU, QUN ZHANG and HONG LI \\ Department of Plastic and Reconstructive Surgery, Shanghai 9th People's Hospital, School of Medicine, \\ Shanghai JiaoTong University, Shanghai Key Laboratory of Tissue Engineering, \\ National Tissue Engineering Center of China, Shanghai 200011, P.R. China
}

Received September 9, 2013; Accepted November 11, 2013

DOI: $10.3892 / \mathrm{mmr} .2013 .1796$

\begin{abstract}
Hair follicle stem cells (HFSCs) possess powerful expansion and multi-differentiation potential, properties that place them at the forefront of the field of tissue engineering and stem cell-based therapy. The aim of the present study was to investigate the differentiation of human HFSCs (hHFSCs) into cells of an endothelial lineage. hHFSCs were expanded to the second passage in vitro and then induced by the addition of vascular endothelial growth factor (VEGF) and basic fibroblast growth factor (bFGF) to the culture medium. The expression levels of endothelial cell (EC)-related markers, including von Willebrand factor (vWF), vascular endothelial cadherin (VE)-cadherin and cluster of differentiation (CD)31, were detected by immunofluorescence staining, flow cytometric analysis and reverse transcription-polymerase chain reaction. The hHFSCs expressed vWF, VE-cadherin and CD31 when exposed to a differentiation medium, similar to the markers expressed by the human umbilical vein ECs. More significantly, differentiated cells were also able to take up low-density lipoprotein. The data of the present study demonstrated that an efficient strategy may be developed for differentiating hHFSCs into ECs by stimulation with VEGF and bFGF. Thus, hHFSCs represent a novel cell source for vascular tissue engineering and studies regarding the treatment of various forms of ischaemic vascular disease.
\end{abstract}

Correspondence to: Professor Qun Zhang, Department of Plastic and Reconstructive Surgery, Shanghai 9th People's Hospital, School of Medicine, Shanghai JiaoTong University, Shanghai Key Laboratory of Tissue Engineering, National Tissue Engineering Center of China, 639 Zhi Zao Ju Road, Shanghai 200011, P.R. China E-mail: zhangqunmd@163.com

Key words: hair follicle stem cells, endothelial cells, vascular tissue engineering

\section{Introduction}

As the human lifespan increases, cardiovascular diseases are starting to represent a growing health and socioeconomic burden to society (1). Among the therapeutic strategies for such diseases, autologous grafts, including autologous saphenous vein and mammary artery grafts, are the common options (2). However, these approaches are limited by the sources and donor site morbidity, and such synthetic grafts, including expanded polytetrafluoroethylene and Dacron (polyethylene terephthalate fibre) grafts, can often result in immunological and thrombotic complications, particularly in the repair of small-diameter vascular defects (3). Research has been conducted on tissue-engineered, small-diameter vascular grafts or the endothelialisation of the previously mentioned artificial grafts, with endothelial cells (ECs) playing a significant role, particularly with regard to vascular tissue engineering applications (4). However, the limited availability of ECs hampers the development of a suitable vascular graft. Furthermore, the slow expansion rate and limited proliferation capability of fully mature ECs in vitro have presented crucial hurdles in their therapeutic use (5).

Offering the unique advantages of proliferative and growth potential, stem cells, either embryonic or adult, and circulating endothelial progenitors have been widely analysed as possible sources of ECs (6,7). Previous studies have indicated that the hair follicle $(\mathrm{HF})$ is a readily accessible mini-organ within the skin that contains stem cells with notably broad differentiation potential, and that it may be an alternative source of autologous ECs $(8,9)$. HF stem cells (HFSCs) have the broad potential to differentiate into adipogenic, osteogenic, chondrogenic, neurogenic and myogenic lineages under the appropriate conditions (10-13). When compared with other stem cells, including embryonic, bone marrow-derived or adipose stem cells, HFSCs are easier to acquire (less invasive) and have a lower associated risk of donor site morbidity and a higher yield at harvest (9). Thus, HFSCs could be a preferred, novel cell source for blood vessel engineering.

Vascular endothelial growth factor (VEGF) is a signalling protein produced by cells that stimulates vasculogenesis and angiogenesis (14). The VEGF family is composed of at least 
seven members, with VEGF-A (normally termed VEGF) being the most significant. The targeted inactivation of the VEGF gene in mice has been shown to cause fatal deficiencies in vascularisation (15), demonstrating the important role of VEGF in this process. VEGF has been shown to affect EC differentiation in vitro (16) and is thus a component of in vitro EC differentiation media (17-19).

Basic fibroblast growth factor (bFGF), also known as FGF2 or FGF- $\beta$, is a member of the FGF family (20). bFGF promotes EC proliferation and the physical organisation of ECs into tube-like structures, and is thus critical in mediating the formation of novel blood vessels and promoting angiogenesis (21).

The aim of the present study was to investigate the potential of human HFSCs (hHFSCs) to differentiate into the EC phenotype upon induction with VEGF and bFGF in a low-serum medium. The gene and protein expression of several characteristic EC markers was examined in the resulting hHFSCs. In addition, a low-density lipoprotein (LDL) uptake function of the induced hHFSCs was also demonstrated.

\section{Materials and methods}

Isolation and culture of hHFSCs. hHFSCs were isolated from human scalp tissues from healthy adult patients undergoing cosmetic plastic surgery, as described previously (22). All the protocols of human tissue handling were approved by the Research Ethical Committee of the hospital and written informed consent was obtained from all patients. hHFSCs at the second passage were used in the subsequent study. The characterisation of the hHFSCs was determined by their CD marker profile (K15, K19, integrin $\beta 1$ ) and their ability to differentiate into osteogenic, adipogenic and chondrogenic lineages (data not shown), as reported previously $(10,11)$.

Induction of EC differentiation. Cells reaching subconfluence were cultured in EC growth medium-2 (EGM-2; Lonza, Walkersville, MD, USA) supplemented with $50 \mathrm{ng} / \mathrm{ml}$ recombinant human VEGF (R\&D Systems, Minneapolis, MN, USA) and $10 \mathrm{ng} / \mathrm{ml}$ recombinant human bFGF (Sigma-Aldrich, St. Louis, MO, USA), with $2 \%$ foetal bovine serum (FBS; HyClone, Logan, UT, USA). EGM-2 supplemented with $2 \%$ FBS was defined as the basal medium (BM). Human umbilical vein ECs (hUVECs) were used as a positive control. The culture media were changed every 2 days. The cell characterisation and functional evaluation were performed subsequent to 7 days of culture.

Immunofluorescence staining. hHFSCs were harvested, resuspended in phosphate-buffered saline (PBS), fixed with $4 \%$ paraformaldehyde for 15 min and permeabilised with $0.1 \%$ Triton X-100 (both Sigma-Aldrich) for $10 \mathrm{~min}$. Subsequent to washing with PBS, the cells were blocked with $3 \%$ bovine serum albumin (BSA) for $30 \mathrm{~min}$ and then incubated with the following primary antibodies: Rabbit polyclonal anti-von Willebrand Factor (vWF, F3520), rabbit polyclonal anti-vascular endothelial cadherin (VE-cadherin, V1514) and mouse monoclonal anti-CD31 (P8590) (all from Sigma-Aldrich). Following incubation with the primary antibodies for $60 \mathrm{~min}$ at room temperature, the cultures were washed with PBS three times. Fluorescein isothiocyanate (FITC)-conjugated goat anti-rabbit secondary antibody (Millipore, Billerica, MA, USA) was used to detect the localisation of the anti-vWF and anti-VE-cadherin antibodies, and FITC-conjugated goat anti-mouse secondary antibody (Millipore) was used to detect the localisation of the anti-CD31 antibodies. The cell nuclei were stained with propidium iodide. The control samples consisted of cells without primary antibodies and were used to assess the background fluorescence. The images were viewed with a fluorescence microscope (Nikon, Tokyo, Japan).

Flow cytometric analysis. The cells were trypsinised, centrifuged at $500 \mathrm{x}$ g for $5 \mathrm{~min}$ (Allegra 64R; Beckman Coulter, Brea, CA, USA), resuspended in PBS/1\% BSA and incubated with anti-vWF, anti-VE-cadherin and anti-CD31 (all from Sigma-Aldrich) for $30 \mathrm{~min}$ at room temperature on a shaking plate (Lab Rotators, Thermo Scientific, Logan, UT, USA). The cells were then washed, resuspended in PBS/1\% BSA with FITC-conjugated secondary antibody and incubated for 30 minutes at room temperature on a shaking plate. The cells were then washed again and fixed, and FITC-conjugated isotype-matching immunoglobulins were used to determine non-specific staining. Fluorescence was determined using a flow cytometer (Becton-Dickinson, San Jose, CA, USA), and the data were analysed using CellQuest software (Becton-Dickinson).

$R N A$ isolation and reverse transcription-polymerase chain reaction $(R T-P C R)$. The expression levels of EC-specific markers (vWF, VE-cadherin and CD31) were identified by isolating the total RNA from the cells using the RNeasy total RNA isolation kit (Qiagen, Inc., Valencia, CA, USA), and cDNA was synthesised using the SuperScript First-strand Synthesis system (Life Technologies, Carlsbad, CA, USA). Specific genes were amplified by PCR using the Fast-Run Taq Master kit (Protech Technology, Taipei, Taiwan). The primer sequences designed using the Primer Express software (Primer Express Software Version 3.0; Applied Biosystems, Foster City, CA, USA) are listed in Table I. The cDNA product was amplified by PCR using standard methods, and electrophoresed through a $2 \%$ agarose gel treated with ethidium bromide; the bands were visualised using an ultraviolet light box. hUVECs and human chondrocyte cells (hCs) were used as the positive and negative controls, respectively.

LDL uptake. LDL uptake was assessed by incubating the cells for $4 \mathrm{~h}$ at $37^{\circ} \mathrm{C}$ with acetylated LDL labelled with 1,10-dioctadecyl-3,3,3',3'-tetramethylindocarbocyanine (DiI-acLDL; Molecular Probes, Biomedical Technologies, Stoughton, MA, USA) diluted to $10 \mu \mathrm{g} / \mathrm{ml}$ in a complete growth medium. The cells were then washed three times with probe-free medium. The incorporation of fluorochrome-labelled LDL into the cells was analysed with an Eclipse E400 Epi-Fluorescence Microscope (Nikon, Tokyo, Japan).

Statistical analysis. Each experiment was repeated at least three times. Since the original data were normally distributed, the results are presented as the mean \pm standard deviation. The comparisons between groups were performed 
Table I. Primers for polymerase chain reaction.

\begin{tabular}{llc}
\hline RNA & \multicolumn{1}{c}{ Primer sequences } & Fragment size, bp \\
\hline vWF & F: 5'-CACCGTTTGCCCACCCTTCG-3' & 433 \\
& R: 5'-GCCCACTGGGAGCCGACACT-3' & \\
VE-cadherin & F: 5'-ACTCACCCCTTGCAATAACG-3' & 250 \\
CD31 & R: 5'-ACAGAGCAGCCATCAGAGGT-3' & \\
& F: 5'-TCCGATGATAACCACTGCAA-3' & 297 \\
& R: 5'-GTGGTGGAGTCTGGAGAGGA-3' & \\
\hline
\end{tabular}

vWF, von Willebrand factor; VE-cadherin, vascular endothelial cadherin; CD31, cluster of differentiation 31.
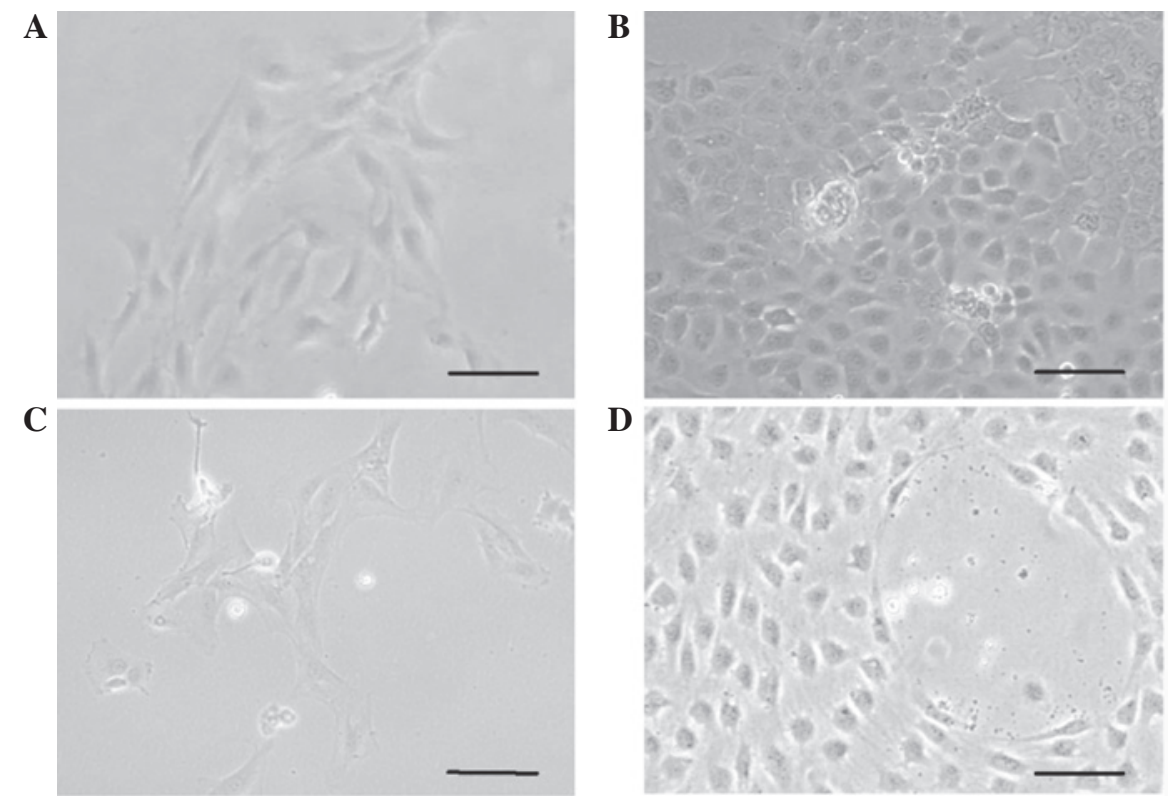

Figure 1. Effect of VEGF and bFGF on hHFSC morphology. (A) Phase-contrast image analysis of cultured hHFSCs. (B) hHFSCs treated with VEGF and bFGF for 7 days. (C) Negative control, hHFSCs treated with basal medium (BM) only. (D) Positive control, primary human umbilical vein endothelial cells (hUVECs). In the presence of VEGF and bFGF, hHFSCs exhibited a morphology similar to that of hUVECs. Scale bar, $100 \mu \mathrm{m}$. VEGF, vascular endothelial growth factor; bFGF, basic fibroblast growth factor; hHFSCs, human hair follicle stem cells.

by a paired Student's t-test and $\mathrm{P}<0.05$ was used to indicate a statistically significant difference. All the statistical analyses were performed using SPSS version 16 (SPSS, Inc., IBM Corporation, Somers, NY, USA).

\section{Results}

Culture of hHFSCs. The total number of cells isolated from each scalp tissue sample ranged between $5 \times 10^{4}$ and $1 \times 10^{5}$ cells. In total, $0.5-2 \%$ of the isolated cells were found to be adherent stem cells. The hHFSCs elongated subsequent to 1-2 days of culture in plates (Fig. 1A); the cells reached confluency within another 3-4 days and were subsequently passaged onto a novel plate.

VEGF and bFGF induce the differentiation of hHFSCs to ECs. At the second passage, $50 \mathrm{ng} / \mathrm{ml}$ VEGF and $10 \mathrm{ng} / \mathrm{ml}$ $\mathrm{bFGF}$ were used to induce the differentiation of hHFSCs to the EC lineage. The hHFSCs acquired a cobblestone morphology subsequent to treatment with VEGF and bFGF for 7 days, similar to the previous observations in primary isolated hUVECs. No evident change was found in the hHFSCs cultured in BM (Fig. 1B-D). At the fourth passage, the hHFSCs appeared to comprise a relatively homogenous population that exhibited an endothelial lineage morphology.

Expression of EC-specific markers in hHFSCs treated with $V E G F$ and $b F G F$. To determine whether VEGF and bFGF can induce the differentiation of hHFSCs to the EC phenotype, EC-specific proteins (vWF, VE-cadherin and CD31) were detected by immunofluorescence staining. These three markers were also examined in hUVECs as a positive control. As shown in Fig. 2, there was little expression of vWF, VE-cadherin or CD31 in the undifferentiated hHFSCs cultured in BM. However, when cultured in EGM-2 supplemented with VEGF and bFGF, the expression levels of vWF, VE-cadherin and CD31 were enhanced, reaching a level similar to that of the hUVECs.

To determine the percentage of EC-differentiated cells in the hHFSC population, the expression levels of vWF, VE-cadherin and CD31 were also analysed using flow cytometry. As shown 


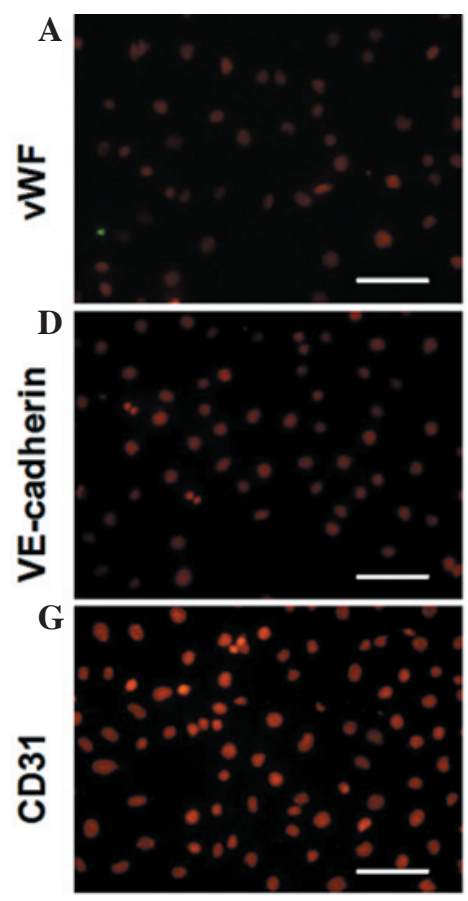

BM
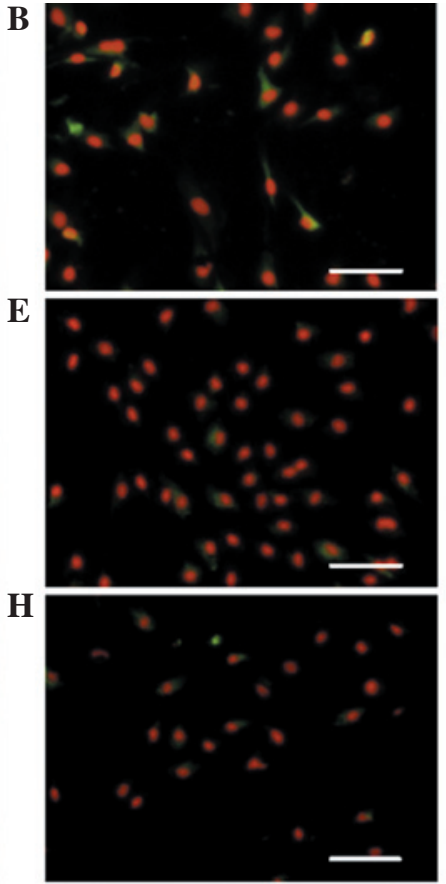

VEGF+bFGF
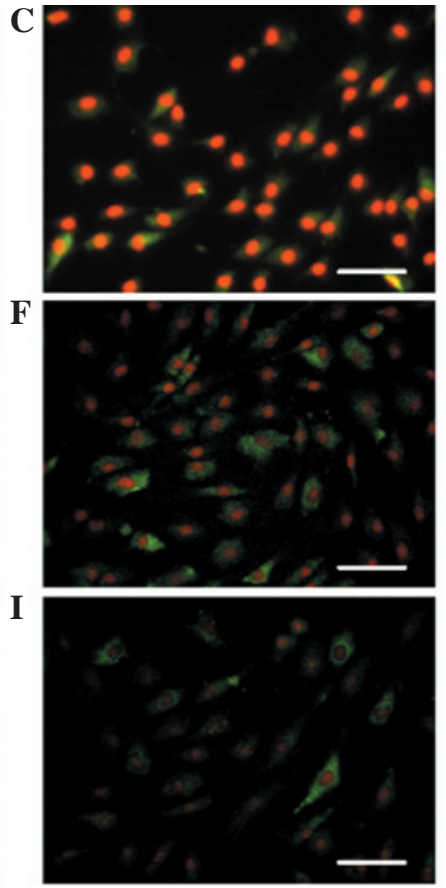

hUVECs

Figure 2. Expression of EC-specific proteins (vWF, VE-cadherin and CD31) under different conditions by immunofluorescent staining. There was little expression of (A) vWF, (D) VE-cadherin or (G) CD31 in the undifferentiated hHFSCs cultured in BM. The expression of (B) vWF, (E) VE-cadherin and (H) CD31 was enhanced when cultured in BM supplemented with VEGF and bFGF, reaching a level similar to that of (C, F, I) the hUVECs. Scale bar, $100 \mu \mathrm{m}$. EC, endothelial cells; vWF, von Willebrand factor; VE-cadherin, vascular endothelial cadherin; hHFSCs, human hair follicle stem cells; BM, basal medium; VEGF, vascular endothelial growth factor; bFGF, basic fibroblast growth factor; hUVECs, human umbilical vein ECs; CD31, cluster of differentiation 31.
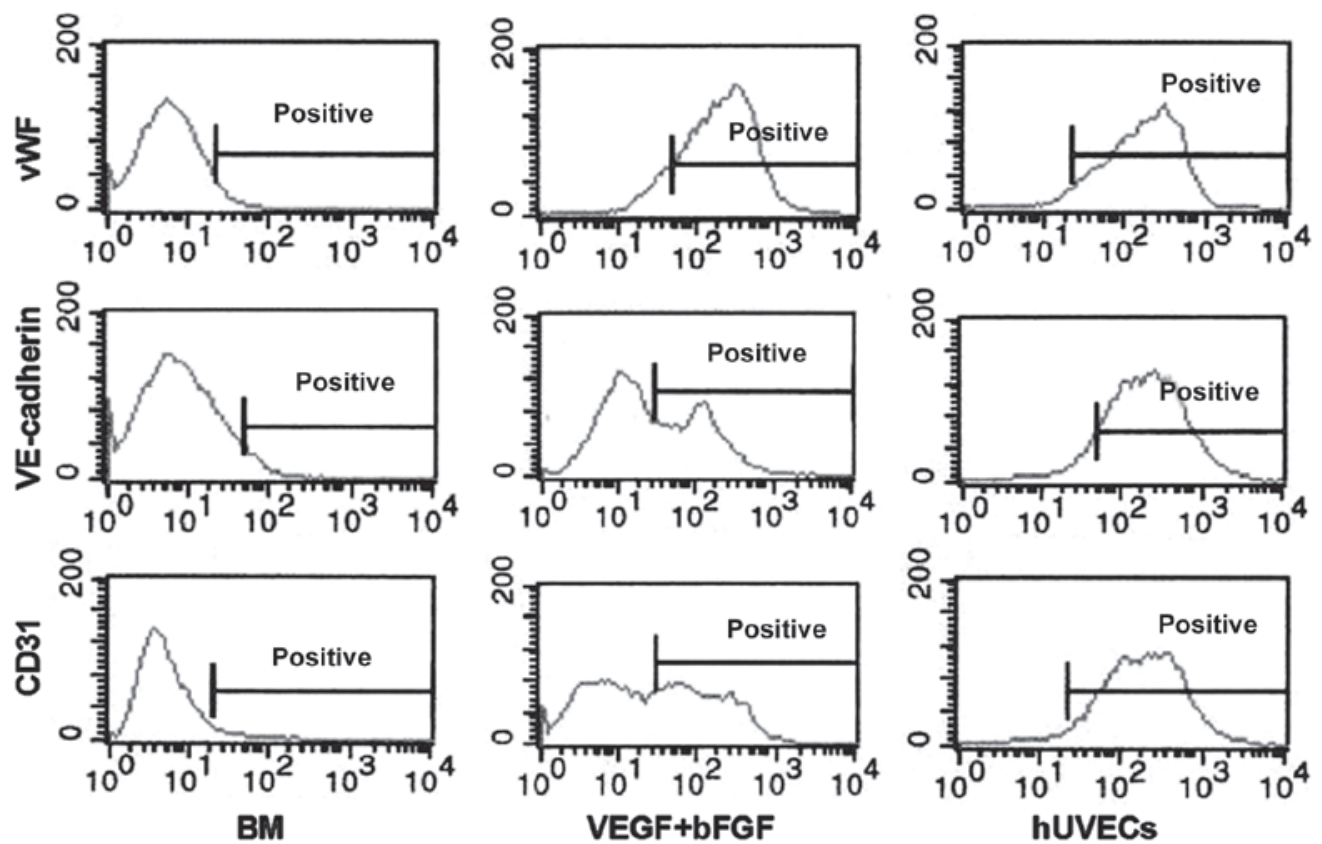

Figure 3. Flow cytometry analysis of EC-specific proteins. Low levels of expression of vWF, VE-cadherin and CD31 were found in the undifferentiated hHFSCs cultured in BM. The expression was enhanced in BM supplemented with VEGF and bFGF, similar to that in hUVECs. EC, endothelial cells; vWF, von Willebrand factor; VE-cadherin, vascular endothelial cadherin; hHFSCs, human hair follicle stem cells; BM, basal medium; VEGF, vascular endothelial growth factor; bFGF, basic fibroblast growth factor; hUVECs, human umbilical vein ECs; CD31, cluster of differentiation 31.

in Fig. 3, vWF was detected in $3.57 \pm 0.47,85.41 \pm 1.42$ and $93.62 \pm 0.75 \%$ of undifferentiated hHFSCs, induced hHFSCs and hUVECs, respectively. By comparison, little expression of VE-cadherin $(3.38 \pm 0.52 \%)$ or CD31 $(2.63 \pm 0.56 \%)$ was found in the undifferentiated hHFSCs, although their expression levels reached $72.36 \pm 1.93$ and $76.49 \pm 1.12 \%$, respectively, in the induced hHFSCs, which is much closer to the expression observed in the hUVECs. 


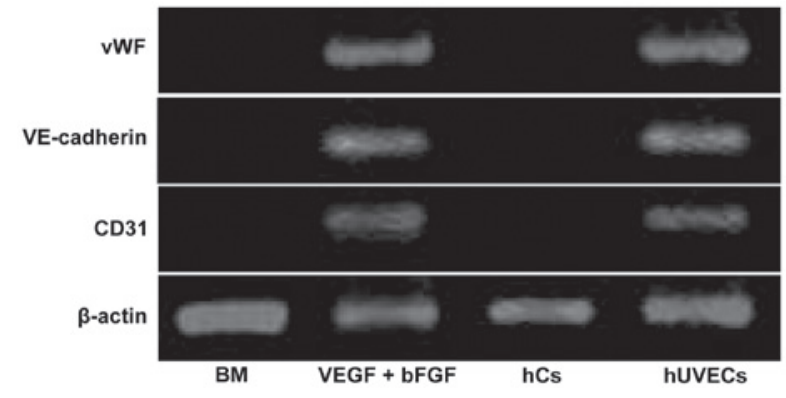

Figure 4. mRNA levels of vWF, VE-cadherin, CD31 and $\beta$-actin were determined by reverse transcription polymerase chain reaction (RT-PCR). The expression of vWF, VE-cadherin and CD31 was observed in hHFSCs induced by VEGF and bFGF, similar to hUVECs. Human chondrocyte cells (hCs) were used as the negative controls. vWF, von Willebrand factor; VE-cadherin, vascular endothelial cadherin; hHFSCs, human hair follicle stem cells; VEGF, vascular endothelial growth factor; bFGF, basic fibroblas growth factor; hUVECs, human umbilical vein ECs; CD31, cluster of differentiation 31 .
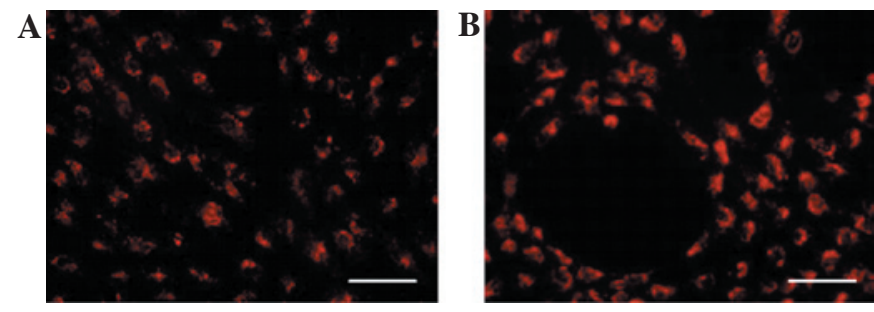

Figure 5. DiI-Ac-LDL incorporation by ECs differentiated from hHFSCs. (A) The cytoplasm of the differentiated cells was fluorescent due to the incorporation of DiI-Ac-LDL. (B) Human umbilical vascular endothelial cells (HUVECs) served as a positive control. Scale bar, $100 \mu \mathrm{m}$. DiI-Ac-LDL, 1,10-dioctadecyl-3,3,3',3'-tetramethylindocarbocyanine; ECs, endothelial cells; hHFSCs, human hair follicle stem cells; HUVECs, human umbilical vein ECs.

The gene expression profile analysed by RT-PCR further confirmed the EC differentiation of the hHFSCs. As shown in Fig. 4, the undifferentiated hHFSCs did not express vWF, VE-cadherin or CD31, similar to the observations in the hCs. By contrast, these factors were upregulated in the induced hHFSCs to a similar level as that in the hUVECs. All the data support the hypothesis that hHFSCs can differentiate into ECs upon exposure to VEGF and bFGF.

Differentiated cells can take up DiI-Ac-LDL. The cytoplasm of the differentiated cells was fluorescent due to the incorporation of labelled LDL (DiI-Ac-LDL; Fig. 5A), a typical ability of ECs, whereas the undifferentiated cells were unable to incorporate the fluorescent DiI-Ac-LDL molecules (data not shown). Parallel experiments were performed with the hUVECs serving as a positive control (Fig. 5B).

\section{Discussion}

Regardless of the results obtained from using adult blood vessel-derived ECs in vascular tissue engineering and regenerative medicine (23-28), their general use is hampered by their inadequate proliferation capacity and lack of autologous sources. Considering the procurement risk and their short lifespan, researchers have urgently been searching for alternative sources of rapidly proliferating and ready-to-use ECs. Although ECs can be derived from multipotent adult stem cells $(5,29-33)$, the potential of HFSCs has been less frequently investigated.

In the present study, the effect of VEGF and bFGF was demonstrated on the differentiation of hHFSCs to the EC lineage. A considerable variation in the expression of the EC markers, vWF, VE-cadherin and CD31, was observed at the gene and protein levels. Nonetheless, VEGF and bFGF induced the expression of these three proteins in the hHFSCs. vWF is a blood glycoprotein uniquely secreted by vascular ECs that binds to connective tissue and recruits platelets to the sites of vascular injury. Thus, vWF is of great importance to haemostasis $(34,35)$. VE-Cadherin is a strictly EC adhesive transmembrane molecule that is specifically expressed at interendothelial junctions and is significant in EC biology as it maintains control of the cohesion and organisation of intercellular junctions (36). CD31, also known as platelet EC adhesion molecule-1, is a transmembrane glycoprotein expressed on the surface of ECs, platelets and certain haematopoietic cells (37). CD31 is generally localised to sites of cell-cell contact in confluent EC monolayers, contributing to vascular permeability, coagulation and leukocyte transmigration (38). Additionally, according to the immunofluorescence staining in the present study, the three markers were still expressed in the differentiated hHFSCs subsequent to 21 days of induction and observation (data not shown). The results of the present study indicate that hHFSCs are fully induced to an endothelial lineage by VEGF and bFGF.

VEGF is a major regulator of vascular development and vascular progenitor cell differentiation in the initial phase of blood vessel development (39), and is a potent mitogen in embryonic and somatic angiogenesis, with a unique specificity for vascular ECs (40). The central role of VEGF in embryonic angiogenesis was demonstrated by the observation that heterozygote knockout mice suffer fatal deficiencies in vascularisation, resulting in embryonic lethality $(41,42)$. VEGF deficiency led to early vascular development disorders, including vasculogenesis, angiogenesis and large vessel formation. The role of VEGF in angiogenesis indicates that this protein could be used to augment collateral vessel formation as an alternative to reconstructive surgery (43), as confirmed by the finding that treatment with DNA encoding VEGF augmented collateral vessel formation in acute limb ischaemia through therapeutic in situ neovascularisation and angiogenesis (44-47). Knowledge of the function of VEGF in endothelial differentiation and blood vessel growth stimulation may be useful for vascular tissue engineering and regenerative medicine, including the treatment of myocardial and lower limb ischaemia, wound healing and skin grafting.

It has been well documented that bFGF is an extracellular matrix component required for supporting EC growth and promoting the formation of differentiated capillary tubes $(48,49)$. bFGF-mediated signalling is critical for the proliferation of the haemangioblast and thus positively regulates haematopoietic development (50). Several lines of evidence have indicated that bFGF (FGF2) stimulates VEGF expression in ECs (51-53). In the absence of bFGF signalling, it leads to the loss of adherens and tight junctions, increased vascular leakiness and disassembly of the existing vasculature.

The mechanism for EC differentiation induced by the angiogenic growth factors, VEGF and bFGF, has been 
extensively investigated. These factors exert their effects by specifically binding to cell surface-expressed receptors, which are ligand-stimulatable tyrosine kinases. The stimulation of receptor kinase activity allows coupling to the downstream signalling transduction pathways, which results in transcriptional changes and biological responses, thereby regulating the proliferation, migration and differentiation of ECs (54). Previous studies have also demonstrated that bFGF stimulates VEGF expression in ECs. One key factor in FGF-induced VEGF expression is the Shc protein, an adaptor molecule recruited to FGFRs upon activation, which is crucial in receptor tyrosine kinase-dependent VEGF gene expression $(55,56)$. Therefore, it was speculated that cross-talk between VEGF and bFGF pathways may contribute to the differentiation of hHFSCs to ECs.

To confirm a differentiated EC phenotype, the demonstration of characteristic functional properties is required. In the present study, the hHFSCs differentiated with VEGF and bFGF were shown to gain the capability of transporting LDL as endothelial differentiation progressed. These data indicate that hHFSCs can be induced to differentiate into an EC phenotype with conventional function when stimulated by VEGF and bFGF in combination. Therefore, hHFSCs may be a valuable source of functional ECs for vascular tissue engineering and therapeutic vasculogenesis.

In conclusion, the present study demonstrated that expanded hHFSCs acquire several endothelial-like characteristics when cultured with VEGF and bFGF for 7 days in vitro, as evidenced by the expression of EC-specific transcripts and proteins, including vWF, VE-cadherin and CD31, and the ability to incorporate fluorescent DiI-Ac-LDL molecules. It was hypothesised that this approach has potential applications for using hHFSCs as a candidate in cardiovascular tissue engineering, and that it provides a tool for various clinical studies in which improved vascularisation is desired.

\section{Acknowledgements}

This study was supported by the National Natural Science Foundation of China (grant no. 81000842). The authors also appreciate the technical support of Dr Demin Ying, Dr Lijuan Zong and Dr Bing Zhong in the laboratory.

\section{References}

1. Owens GK, Kumar MS and Wamhoff BR: Molecular regulation of vascular smooth muscle cell differentiation in development and disease. Physiol Rev 84: 767-801, 2004.

2. Sundaram S and Niklason LE: Smooth muscle and other cell sources for human blood vessel engineering. Cells Tissues Organs 195: 15-25, 2012.

3. Xu ZC, Zhang WJ, Li H, Cui L, Cen L, Zhou GD, Liu W and Cao Y: Engineering of an elastic large muscular vessel wall with pulsatile stimulation in bioreactor. Biomaterials 29:1464-1472, 2008.

4. Poh M, Boyer M, Solan A, Dahl SL, Pedrotty D, Banik SS, McKee JA, Klinger RY, Counter CM and Niklason LE: Blood vessels engineered from human cells. Lancet 365: 2122-2124, 2005.

5. McKee JA, Banik SS, Boyer MJ, Hamad NM, Lawson JH, Niklason LE and Counter CM: Human arteries engineered in vitro. EMBO Rep 4: 633-638, 2003.

6. Bajpai VK and Andreadis ST: Stem cell sources for vascular tissue engineering and regeneration. Tissue Eng Part B Rev 18: $405-425,2012$
7. Matsumura G, Miyagawa-Tomita S, Shin'oka T, Ikada Y and Kurosawa H: First evidence that bone marrow cells contribute to the construction of tissue-engineered vascular autografts in vivo. Circulation 108: 1729-1734, 2003.

8. Shin'oka T, Matsumura G, Hibino N, Naito Y, Watanabe M, Konuma T, Sakamoto T, Nagatsu M and Kurosawa H: Midterm clinical result of tissue-engineered vascular autografts seeded with autologous bone marrow cells. J Thorac Cardiovasc Surg 129: 1330-1338, 2005.

9. Gong ZD and Niklason LE: Small-diameter human vessel wall engineered from bone marrow-derived mesenchymal stem cells (hMSCs). FASEB J 22: 1635-1648, 2008.

10. Heydarkhan-Hagvall S, Schenke-Layland K, Yang JQ, Heydarkhan S, Xu Y, Zuk PA, MacLellan WR and Beygui RE: Human adipose stem cells: a potential cell source for cardiovascular tissue engineering. Cells Tissues Organs 187: 263-274, 2008.

11. Wang C, Cen L, Yin S, Liu Q, Liu W, Cao Y and Cui L: A small diameter elastic blood vessel wall prepared under pulsatile conditions from polyglycolic acid mesh and smooth muscle cells differentiated from adipose-derived stem cells. Biomaterials 31: 621-630, 2010.

12. Harris LJ, Abdollahi H, Zhang P, McIlhenny S, Tulenko TN and DiMuzio PJ: Differentiation of adult stem cells into smooth muscle for vascular tissue engineering. J Surg Res 168: 306-314, 2011.

13. Hsu YC, Pasolli HA and Fuchs E: Dynamics between stem cells, niche, and progeny in the hair follicle. Cell 144: 92-105, 2011.

14. Mistriotis P and Andreadis ST: Hair Follicle: a novel source of multipotent stem cells for tissue engineering and regenerative medicine. Tissue Eng Part B Rev 19: 265-278, 2013.

15. Jahoda CA, Whitehouse J, Reynolds AJ and Hole N: Hair follicle dermal cells differentiate into adipogenic and osteogenic lineages. Exp Dermatol 12: 849-859, 2003.

16. Yu H, Fang D, Kumar SM, Li L, Nguyen TK, Acs G, Herlyn M and $\mathrm{Xu} \mathrm{X}$ : Isolation of a novel population of multipotent adult stem cells from human hair follicles. Am J Pathol 168: 1879-1888, 2006.

17. Drewa T, Joachimiak R, Kaznica A, Sarafian V and Pokrywczynska M: Hair stem cells for bladder regeneration in rats: preliminary results. Transplant Proc 41: 4345-4351, 2009.

18. Lin H, Liu F, Zhang C, Zhang Z, Kong Z, Zhang X and Hoffman RM: Characterization of nerve conduits seeded with neurons and Schwann cells derived from hair follicle neural crest stem cells. Tissue Eng Part A 17: 1691-1698, 2011.

19. Dickson MC, Martin JS, Cousins FM, Kulkarni AB, Karlsson S and Akhurst RJ: Defective haematopoiesis and vasculogenesis in transforming growth factor-beta 1 knock out mice. Development 121: 1845-1854, 1995.

20. Shah NM, Groves AK and Anderson DJ: Alternative neural crest cell fates are instructively promoted by TGFbeta superfamily members. Cell 85: 331-343, 1996.

21. Grainger DJ, Metcalfe JC, Grace AA and Mosedale DE: Transforming growth factor-beta dynamically regulates vascular smooth muscle differentiation in vivo. J Cell Sci 111: 2977-2988, 1998.

22. Hirschi KK, Rohovsky SA and D'Amore PA: PDGF, TGFbeta, and heterotypic cell-cell interactions mediate endothelial cell-induced recruitment of 10T1/2 cells and their differentiation to a smooth muscle fate. J Cell Biol 141: 805-814, 1998.

23. Chen $\mathrm{S}$ and Lechleider RJ: Transforming growth factor-beta-induced differentiation of smooth muscle from a neural crest stem cell line. Circ Res 94: 1195-1202, 2004.

24. Hirschi KK, Burt JM, Hirschi KD and Dai C: Gap junction communication mediates transforming growth factor-beta activation and endothelial-induced mural cell differentiation. Circ Res 93: 429-437, 2003.

25. Ross JJ, Hong Z, Willenbring B, Zeng L, Isenberg B, Lee EH, Reyes M, Keirstead SA, Weir EK, Tranquillo RT and Verfaillie CM: Cytokine-induced differentiation of multipotent adult progenitor cells into functional smooth muscle cells. J Clin Invest 116: 3139-3149, 2006.

26. Lindahl P, Johansson BR, Levéen P and Betsholtz C: Pericyte loss and microaneurysm formation in PDGF-B-deficient mice. Science 277: 242-245, 1997.

27. Hellström M, Kalén M, Lindahl P, Abramsson A and Betsholtz C: Role of PDGF-B and PDGFR-beta in recruitment of vascular smooth muscle cells and pericytes during embryonic blood vessel formation in the mouse. Development 126: 3047-3055, 1999.

28. Kim YM, Jeon ES, Kim MR, Jho SK, Ryu SW and Kim JH: Angiotensin II-induced differentiation of adipose tissue-derived mesenchymal stem cells to smooth muscle-like cells. Int J Biochem Cell Biol 40: 2482-2491, 2008. 
29. Long JL and Tranquillo RT: Elastic fiber production in cardiovascular tissue-equivalents. Matrix Biol 22: 339-350, 2003.

30. Gong $\mathrm{Z}$ and Niklason LE: Blood vessels engineered from human cells. Trends Cardiovasc Med 16: 153-156, 2006.

31. Isenberg BC, Williams C and Tranquillo RT: Small-diameter artificial arteries engineered in vitro. Circ Res 98: 25-35, 2006.

32. Cho SW, Lim SH, Kim IK, Hong YS, Kim SS, Yoo KJ, Park HY, Jang Y, Chang BC, Choi CY, et al: Small-diameter blood vessels engineered with bone marrow-derived cells. Ann Surg 241: 506-515, 2005 .

33. Rodriguez LV, Alfonso Z, Zhang R, Leung J, Wu B and Ignarro LJ: Clonogenic multipotent stem cells in human adipose tissue differentiate into functional smooth muscle cells. Proc Natl Acad Sci USA 103: 12167-12172, 2006.

34. Beltrami AP, Cesselli D, Bergamin N, Marcon P, Rigo S, Puppato E, D'Aurizio F, Verardo R, Piazza S, Pignatelli A, et al: Multipotent cells can be generated in vitro from several adult human organs (heart, liver, and bone marrow). Blood 110 3438-3446, 2007.

35. Miano JM: Mammalian smooth muscle differentiation: origins, markers and transcriptional control. Results Probl Cell Differ 38 $39-59,2002$.

36. Grainger DJ: Transforming growth factor beta and atherosclerosis: so far, so good for the protective cytokine hypothesis. Arterioscler Thromb Vasc Biol 24: 399-404, 2004.

37. Björkerud S: Effects of transforming growth factor-beta 1 on human arterial smooth muscle cells in vitro. Arterioscler Thromb 11: 892-902, 1991.

38. Deaton RA, Su C, Valencia TG and Grant SR: Transforming growth factor-betal-induced expression of smooth muscle marker genes involves activation of PKN and p38 MAPK. J Biol Chem 280: 31172-31181, 2005.

39. Hautmann MB, Madsen CS and Owens GK: A transforming growth factor beta (TGFbeta) control element drives TGFbeta-induced stimulation of smooth muscle alpha-actin gene expression in concert with two CArG elements. J Biol Chem 272: 10948-10956, 1997.

40. Kawai-Kowase K, Sato H, Oyama Y, Kanai H, Sato, M, Doi H and Kurabayashi M: Basic fibroblast growth factor antagonizes transforming growth factor-beta1-induced smooth muscle gene expression through extracellular signal-regulated kinase $1 / 2$ signaling pathway activation. Arterioscler Thromb Vasc Biol 24:1384-1390, 2004.

41. Papetti M, Shujath J, Riley KN and Herman IM: FGF-2 antagonizes the TGF-betal-mediated induction of pericyte alpha-smooth muscle actin expression: a role for myf-5 and Smad-mediated signaling pathways. Invest Ophthalmol Vis Sci 44: 4994-5005, 2003

42. Kucich U, Rosenbloom JC, Abrams WR, Bashir MM and Rosenbloom J: Stabilization of elastin mRNA by TGF-beta initial characterization of signaling pathway. Am J Respir Cell Mol Biol 17: 10-16, 1997.
43. Kucich U, Rosenbloom JC, Abrams WR and Rosenbloom J: Transforming growth factor-beta stabilizes elastin mRNA by a pathway requiring active Smads, protein kinase C-delta, and p38. Am J Respir Cell Mol Biol 26: 183-188, 2002.

44. Hong HH, Uzel MI, Duan C, Sheff MC and Trackman PC: Regulation of lysyl oxidase, collagen, and connective tissue growth factor by TGF-beta1 and detection in human gingiva. Lab Invest 79: 1655-1667, 1999.

45. Ross JJ and Tranquillo RT: ECM gene expression correlates with in vitro tissue growth and development in fibrin gel remodeled by neonatal smooth muscle cells. Matrix Biol 22: 477-490, 2003.

46. Yao L, Swartz DD, Gugino SF, Russell JA and Andreadis ST: Fibrin-based tissue-engineered blood vessels: differential effects of biomaterial and culture parameters on mechanical strength and vascular reactivity. Tissue Eng 11: 991-1003, 2005

47. Sinha S, Hoofnagle MH, Kingston PA, McCanna ME and Owens GK: Transforming growth factor-betal signaling contributes to development of smooth muscle cells from embryonic stem cells. Am J Physiol Cell Physiol 287: C1560-C1568, 2004.

48. Kinner B, Zaleskas JM and Spector M: Regulation of smooth muscle actin expression and contraction in adult human mesenchymal stem cells. Exp Cell Res 278: 72-83, 2002.

49. Wang D, Park JS, Chu JS, Krakowski A, Luo K, Chen DJ and $\mathrm{Li}$ S: Proteomic profiling of bone marrow mesenchymal stem cells upon transforming growth factor beta1 stimulation. J Biol Chem 279: 43725-43734, 2004.

50. Collins T, Pober JS, Gimbrone MA Jr,Hammacher A, Betsholtz C, Westermark B and Heldin CH: Cultured human endothelial cells express platelet-derived growth factor A chain. Am J Pathol 126: 7-12, 1987.

51. Westermark B, Siegbahn A, Heldin CH and Claesson-Welsh L: B-type receptor for platelet-derived growth factor mediates a chemotactic response by means of ligand-induced activation of the receptor protein-tyrosine kinase. Proc Natl Acad Sci USA 87:128-132, 1990.

52. Holmgren L, Glaser A, Pfeifer-Ohlsson S and Ohlsson R: Angiogenesis during human extraembryonic development involves the spatiotemporal control of PDGF ligand and receptor gene expression. Development 113: 749-754, 1991.

53. Hyytiäinen M, Penttinen C and Keski-Oja J: Latent TGF-beta binding proteins: extracellular matrix association and roles in TGF-beta activation. Crit Rev Clin Lab Sci 41: 233-264, 2004.

54. Derynck R and Akhurst RJ: Differentiation plasticity regulated by TGF-beta family proteins in development and disease. Nat Cell Biol 9: 1000-1004, 2007.

55. Liang MS and Andreadis ST: Engineering fibrin-binding TGF- $\beta 1$ for sustained signaling and contractile function of MSC based vascular constructs. Biomaterials 32: 8684-8693, 2011

56. Gallagher JT: Heparan sulfate: growth control with a restricted menu. J Clin Invest 108: 357-361, 2001. 